\title{
Investigating the Theoretical Structure of Deliberative Democratic Leadership
}

\author{
Chun-wen Lin \\ Correspondence: Chun-wen Lin, Department of Child Care, National Pingtung University of Science \& Technology, \\ Taiwan.
}

Received: June 21, 2018

doi:10.11114/jets.v6i9.3550
Accepted: August 16, 2018

Online Published: August 17, 2018

URL: https://doi.org/10.11114/jets.v6i9.3550

\begin{abstract}
This paper explores the theoretical framework of teaching deliberative democratic leadership by examining teacher deliberative competency from theories of deliberative democracy. The research described the theoretical framework of deliberative democratic leadership as a heuristic in the practice of teaching deliberative democratic leadership. Through exploratory factor analysis, Teacher Deliberative Competency Scale (TDCS) reduced to 7-factor structure: ethic, inclusion, well-informed, publicity, deliberation, reciprocity and consensus. Results suggest that TDCS provides instructions for teaching deliberative democratic leadership.
\end{abstract}

Keywords: deliberative democratic leadership, deliberative democracy, educational leadership

\section{Introduction}

Educational leadership which is important for school development and reform is undergoing a paradigm shift from traditional view of leadership associated with individual role to multiple sources of leadership (Spillane, 2006 ; Spillane, Camburn, \& Pareja, 2007; Woods, 2004, 2005). Distributed leadership was proposed in the sense that leadership should not converge into one individual, it could disperse within many people (Spillane, 2006 ). Woods (2004: 34), following the tradition of Dewey, further argued democratic leadership which is distinct from distributed leadership in inherent autonomy and integration towards human capacity (Dewey, 1916; Woods \& Gronn, 2009).

In this article, we explore what role deliberative democratic leadership might play in pedagogy. Why we focus on discursive rationality within democratic leadership? Because discursive rationality as deliberation is important for reinforcing democracies, and also enhancing the legitimacy of policy-making, thus, participants engagement in deliberative decision-making upon school affairs may be paramount for creating stakeholders trust, improving actors devotion to goal pursuit, and ultimately, contributing to realization of human potentials. In pluralistic societies, students living in situations of potential conflicts also need to learn to handle and solve conflicts constructively in deliberation through deliberative pedagogy approach (Roth, 2004).

Yang (1996) proposed storytelling provides a vehicle for such a broadening of rhetoric, where the emphasis is placed on narratives, rather than simply objective, disembodied arguments. Jon Elster (1998) indicated that discussion, versus simply having a vote, might improve implementation involves a possible psychological effect. That is to say, the chances to deliberate or discussion may make participant more inclined to support and consensus of the discursion or deliberation.

We first theorize deliberative democratic leadership and associated concepts. Then, using questionnaire survey of Teacher deliberative competency in Taiwan, We analyze 7 dimensions of deliberative democracy leadership in school activity. Finally, we attempt to address the practice of teaching deliberative democracy in school regarding ethic, inclusion, well-informed, publicity, deliberation, reciprocity and consensus.

\section{Literature Review}

Conceptual Approaches to Deliberative Democratic Leadership

Four models of democracy, starting with liberal minimalism, civic republicanism to broader notions of deliberative and developmental democracy were proposed (Stokes, 2002). Based on the above theory, democratic leadership in education which embedded in developmental democracy consists of ethical rationality, discursive rationality, decisional rationality and therapeutic rationality in the principles of freedom, substantive liberty, equality and organic belonging 
was argued in a substantive conception of the person as a social and creative being (Woods, 2004 Backer, 2016). In modern society, while democracy model remains between liberal minimalism and civic republicanism, it might be a utopianism to shift directly from stage one democratic model -- liberal minimalism to stage 4 developmental democracy. The primary aim of a democratic theory or deliberative democracy is not to offer solutions to all the issues or conflicts plaguing our school, but to consider other ways of resolving those conflicts or problems that are compatible with a commitment to democratic values (Gutmann, 1987). Therefore, we argued that deliberative democratic leadership embedded in deliberative democracy should be rudimentary for actually practice and comprehensive realization in education, then it could be possible to promote to higher democratic stage - developmental democracy.

What is deliberative democratic leadership? From literature review, Simonton had described deliberative leadership as the personality of successful American President in deliberative attitude in political action (Simonton, 1986, 1987, 1988, 2006). Gerald also defined the deliberative leadership as deliberative body as student council lead the leadership in school governance (Gerard, 2003). In this article, we define briefly in another way that the deliberative democratic leadership involves practice of educational leadership embedded in deliberative democracy theories. Here come the critical problems. What is the exactly theory of deliberative democracy? Deliberation must not -in effort to differentiate deliberation from bargaining - categorically exclude either self-interest claims or the conflicts that such claims might generate from the range of admissible topics that actors might address (Elster, 1998).The deliberative democracy theory sits squarely in the debate regarding the promising purpose to promote the collective decisions, to encourage public-spirited perspectives on public issues, to reinforce mutually respectful processes of decision-making, and to correct respect (Gutmann \& Thompson, 2004). Thus, deliberative democracy theories have diverse directions; one emphasizes process upon the Habermasian logic of communicative action and rationality(Benhabib, 1996; Habermas, 1996), the other one focus on outcomes with procedure component within flexibility in discourse (Bächtiger, Niemeyer, Neblo, Steenbergen, \& Steiner, 2010). From democratic pedagogy and deliberative pedagogy, we described the practice of deliberative democratic leadership in democracy principles (Woods, 2004) as freedom, equality, substantial liberty and organic belonging through deliberative competency of ethic, inclusion, well-informed, publicity, deliberation, reciprocity and consensus.

\section{The Elements of Deliberative Democratic Leadership in Education}

"Deliberation" benefits from a style of debate or discussion typical of scientific discussion. Science and deliberation share from similar virtues including tentative and required legitimacy by respective justification (Elster, 1998). "Inclusion" represents the importance of including the excluders, which might ask to participate in the process of consensus decision making not made by them. "Publicity: needs to be emphasized by the deliberative procedure must be held under public legitimacy and justification." Reciprocity" was proposed by Amy Gutmann and Dennis Thompson (1996) which means" moral accommodation or disagreement based on a value that lies at the core of reciprocity and deliberation in a democracy --- mutual respect. Like toleration, mutual respect is a agreeing or disagreeing, but mutual respect needs more than toleration, requiring a favorable attitude toward and constructive interaction with the participants with whom one disagree"."Publicity" principle in government is that it promotes democratic deliberation and encourages officials to give reason for decision-making. Publicity prevents the self-interest to the extremity in the discussion. "Well informed" is the foundation of discussion and deliberation. Deliberative democracy can't be equal among participants if the information remained secret to some of them. Egalitarian is not the element of deliberative democratic leadership because the egalitarian principle of opportunity would be unrealistic and undemocratic in its demands Gutmann, \&Ghompson, 1996).

\subsection{Why Teaching Deliberative Democratic Leadership in Education?}

From a film called "Freedom Writers", the young teacher inspired at-risk students to pursue education beyond school and treated students as creators of knowledge by certain form of deliberative democratic leadership. Central to deliberative democratic pedagogy is the deliberative democratization of the decision-making process regarding curriculum. In this view, students might participate in the process of constructing the curriculum. In film, after students finish reading 'The Diary of Anne Frank', teacher Gruwell gave them an assignment to write a letter to Miep Gies. One student, learning that Miep Gies is alive, suggested inviting her to visit the class. The above explains reasons for teaching deliberative democratic leadership. Besides, teaching deliberative democratic leadership promotes the students' motivation and navigational feeling to engage students to pedagogical goals by providing truth and warm (Woods, 2004: 39). It also creates the conditions for democratic pedagogies and leads to open approach to knowledge. Dialogue is a way of teaching for general thinking skills, not only the reasoning skills measured by the tests used but also creativity and learning to learn (Wegerif, 2005). Deliberative democratic leadership combined with democratic pedagogy and deliberative pedagogy also enforces students to critical thinking. It also provides the solutions to conflicts in school. 


\subsection{Aims of Research}

The purpose of this paper is to offer pedagogical guidance for educators teaching leadership in school and present the practice of teaching deliberative democratic leadership in deliberative context based on findings from studies of the Teacher deliberative competency in Taiwan. The first study involved the development of Teacher deliberative competency scale which was then used as the basis for constructing a measuring instrument. Study 2 reports an investigation of the survey of Teacher deliberative competency. According to the survey findings, the practice of teaching deliberative democratic leadership is recommended.

\section{Method}

Participant and Procedure

There has been no previous research explicitly on the Teacher deliberative competency of teachers of any other Asian culture. While most of the research in deliberative democracy has been qualitative in nature there only have been few recent attempts to develop quantitative instruments for measurement of Teacher democratic belief based on teacher-student interaction in classroom (Shechyman, 2002). Accordingly, we designed the contents of questionnaire in 6-point Likert-type scale which explored Teacher deliberative competency in school council or meeting and developed Teacher Deliberative Competency Scale (TDCS) based on essence of deliberative democracy as ethic, inclusion, well-informed, publicity, deliberation, reciprocity and consensus.

The preliminary study on first stage for scale validity was conducted on 248 elementary school teachers from 25 schools by way of random sampling in Taiwan.

On secondary stage, the study carried out on 230 school teachers from 35 schools by way of random sampling. $57.4 \%$ of the teachers were female $(n=132)$ and $42.6 \%$ of them were male $(n=98) .46 .1 \%$ of them were elementary school teachers $(n=106), 14.3 \%$ of them junior high school teachers $(n=33)$, and $37.6 \%$ of them senior high school teachers $(\mathrm{n}=86)$.

\section{Result}

The research was conducted in two stages. The first stage involved analyses of data collect from the first 248 teachers sample (elementary school teachers, Taiwan) for exploratory factor analysis (EFA) for examining the factor structure of the item pool. Accordingly, the second stage involved analyses for the second sample data (230 elementary school, junior high school and senior high school teachers). ANOVA was used to investigate the Teacher deliberative competency. The data collected by the questionnaire were analyzed using the Statistical Package for Social Science (SPSS Version 12.0) for Windows. Completed questionnaires were coded and data were loaded to SPSS-PC for statistical analysis.

Factor Analysis and Reliability

With 248 participants, the ratio of 11 participants per item was higher than minimal recommended ratio of 1: 5 (Gorsuch, 1983). For scale factorability, factor analysis showed that Kaiser-Meyer-Olin (KMO) was .933, greater than minimum of .60. Kaiser (1974) characterizes KMO measures in the 0.90 s as good. Results that are 0.60 or greater indicate that researchers can comfortably proceed with the factor analysis (Kaiser, 1974; Tabachnick \& Fidell, 2001). Bartletts test of sphericity $(\chi 2=2450.56)$, which indicated a very low probability $(\mathrm{p}<.001)$ that the correlations within the matrix of items were zero. The above indicators justified the use of EFA with this sample (Leech, Barrett, \& Morgan, 2005). By promax oblique rotation method, seven factors with 3 items each were attained and labeled as follows: factorI(Ethic; factor loading .982, .820, .772; communalities .955, .694, .780; Cronbach's alpha .923), factorII(Inclusion; factor loading .899, .680, .525; communalities .779, .561, .290; Cronbach's alpha .724), factorIII(Well-informed; factor loading .911, .862, .793; communalities .853, .739, .810; Cronbach's alpha .916), factorIV(Publicity; factor loading .837, .802, .604; communalities .657, .666, .452; Cronbach's alpha .798), factorV(Deliberation; factor loading .901, .734, .700; communalities .793, .601, 493.; Cronbach's alpha .814), factorVI(Reciprocity; factor loading .781, .755, .659; communalities .618, .591, .456; Cronbach's alpha .772), and factorVII(Consensus; factor loading .733, 645, 336; communalities $.535, .435, .303$; Cronbach's alpha .636). The seven factors explain $62.125 \%$ of variance in total 21 items, which indicates that these factors represent the main Teacher deliberative competency.

The internal consistency of the items on the instrument was assessed using the Cronbach

alpha $(\alpha)$ coefficient. The internal consistency was determined on the 21 items in the Teacher Deliberative Competency Scale (TDCS) and overall found to be 0.815 . Thus, the overall reliability of the instrument was ensured. Using the individual as the unit of analysis, scale reliability estimates ranged from 0.636 for the subscale of 'Consensus', to 0.923 for the subscale of 'Ethic', confirming the reliability of each of the seven subscales. Thus, each subscale of the TDCS shows an acceptable degree of internal consistency. The Cronbach's alpha values are ranging from 0.636 to 0.923. 
Overall, the exploratory factor analysis and reliability estimates indicate that the Teacher Deliberative Competency Scale (TDCS) is a valid measurement tool for assessing factors that might be associated with the Taiwanese Teacher deliberative competency.

\section{Teacher Deliberative Competency}

On the secondary stage, we conducted Teacher Deliberative Competency Scale (TDCS) on 230 school teachers from 35 schools for measurement of Teacher deliberative competency. The results revealed the mean scores of the 'Deliberation' subscale (Mean=3.06 $\pm .760 ; \mathrm{N}=230$ ) were lower than other subscale. The mean scores of other subscale from low to high were followed as 'Reciprocity' subscale (Mean=3.48 $\pm .784 ; \mathrm{N}=230$ ); 'Inclusion' subscale (Mean=3.58 \pm .826 ; $\mathrm{N}=230$ ); 'Consensus' subscale (Mean=3.89 $\pm .579 ; \mathrm{N}=230$ ); 'Publicity' subscale (Mean=4.00 $\pm .704 ; \mathrm{N}=230$ ); 'Well-informed' subscale (Mean=4.24 $\pm .783 ; \mathrm{N}=230$ ); 'Ethic' subscale (Mean=4.41 $\pm .727 ; \mathrm{N}=230$ ).

Comparisons of Teacher Deliberative Competency across Sex, Age and School Levels

Sex: Male teachers versus female teachers. Comparison of mean scores of the 'Deliberation' subscale for the male (Mean=3.24 $\pm .737 ; \mathrm{N}=98)$ and female $(\mathrm{Mean}=2.91 \pm .748 ; \mathrm{N}=132)$ teachers on the TDCS indicated that there were statistically significant differences- $\mathrm{F}=11.325, \mathrm{p}<.05, \boldsymbol{\eta}^{2}=0.047$.

Age: Teachers aged between 40 to 49 versus teachers aged below 30. Comparison of mean scores of the 'Deliberation' subscale for aged between 40 to 49 (Mean=3.231 \pm .748 ) and aged below 30 (Mean=2.643 \pm .723 ) teachers on the TDCS indicated that there were statistically significant differences- $\mathrm{F}=4.947, \mathrm{p}<.05, \boldsymbol{\eta}^{2}=0.062$.

Public/ Private School: Public school teachers versus Private school teachers. Comparison of mean scores of the 'Deliberation' subscale for the public (Mean=3.135 $\pm .786 ; \mathrm{N}=173$ ) and private (Mean=2.819 $\pm .787 ; \mathrm{N}=57$ ) teachers on the TDCS indicated that there were statistically significant differences $-F=7.605, p<.05, \boldsymbol{\eta}^{2}=0.032$. Comparison of the mean scores of 'Inclusion' subscale for the public (Mean=3.513 $\pm .832 ; \mathrm{N}=173$ ) and private (Mean=3.789 \pm .782 ; $\mathrm{N}=57$ ) teachers on the TDCS indicated that there were statistically significant differences- $\mathrm{F}=4.852, \mathrm{p}<.05, \boldsymbol{\eta}^{2}=$ 0.021 .

School Level: Elementary school teachers versus junior high school teachers versus senior high school teachers. Comparison of mean scores of the 'Deliberation' subscale for the elementary school teachers(Mean=3.070 \pm .745 ; $\mathrm{N}=106)$, junior high school teachers(Mean=3.323 $\pm .750 ; \mathrm{N}=33$ ) and senior high school teachers (Mean=2.792 \pm .741 ; $\mathrm{N}=40$ ) on the TDCS indicated that there were statistically significant differences $-\mathrm{F}=3.479, \mathrm{p}<.05, \boldsymbol{\eta}^{2}=0.072$.

Experience: Years of teaching. We formed four groups, each based on the number of years that individuals had taught (e.g., less 6 years, 6-12 years, 12-18 years, 19+ years). We conducted analyses of variance (ANOVAs) and showed mean scores of the 'Deliberation' subscale for $19+$ years teachers (Mean=3.360 $\pm .837 ; \mathrm{N}=45$ ) were higher than teaching experience less 6 years teachers (Mean $=2.813 \pm .687 ; \mathrm{N}=68$ ) with statistics significance $-\mathrm{F}=5.545, \mathrm{p}<.05$, $\eta^{2}=0.069$.

\section{Conclusions}

Results support our seven dimensions of Teacher deliberative competency and responses to the Teacher Deliberative Competency Scale (TDCS) instrument were found to be of satisfactory internal consistency reliability, as well as validity. Additional data we collected suggested deliberation subscale (3.06) performed lowest, followed by reciprocity (3.48) and inclusion (3.58). We also found that elder teachers, junior high school teachers as well as more experienced teachers might have higher performance in deliberation subscale. As for limitation for this study, the results of survey in Teacher deliberative competency might differed in some respects from those found in the Western educational institutions due probably to oriental cultural factors which emphasize more on ethics and lack of autonomic deliberation in public.

\section{Recommendations}

The finding that teacher deliberation capability ranked the lowest score suggests that there is a need for teachers teaching deliberative democratic leadership in deliberation context. A discussion of democratic deliberative leadership must not lose sight of the role of teachers, citizens whose political and social character have already shaped and formed by their early education (Gutmann, 1987). It would be beneficial for teachers to play a more constructive role in teaching deliberative democratic leadership to enhance student's active deliberation and guide to open to knowledge as 'authentic pedagogy' which encourage 'students actively constructing knowledge, using disciplined inquiry and finding applications beyond schools for what they have learned' (Glickman, 1998) and directs instruction toward deepest purposes of creative human potential. The second two lowest scores in 'Reciprocity' subscale and 'Inclusion' subscale were found in this study indicate that teaching deliberative democratic leadership should more focus on inclusion minority voices and cultivate the capability of reciprocity. Using the Teacher Deliberative Democracy competency scale 
as an aid to practice deliberative democratic leadership constitute heuristics capable of helping realizing of problems and deficits of leadership. It should also support school leader development by enhancing principals' deliberative democratic competency in terms of:

--- ameliorating the obstacles which maybe non-democratic school culture and structure, adverse political, social forces, resistance from self-interest, apathy and belief in hierarchy., thereby enhancing stakeholders participate in school governance within democratic pedagogy(Woods, 2004 ;Samuelsson, 2016).

---identifying processes, such as school meetings, that could facilitate deliberative pedagogies and practice the deliberative competency as reciprocity, inclusion, ethic, well-informed, publicity, deliberation and consensus.

\section{Reference}

Backer, D. I. (2016). Elements of discussion. Charlotte, NC: Information Age Publishing.

Bächtiger, A., Niemeyer, S., Neblo, M., Steenbergen, M. R., \& Steiner, J. (2010). Disentangling diversity in deliberative democracy: Competing theories, their blind spots and complementarities. Journal of Political Philosophy, 18(1), 32-63. https://doi.org/10.1111/j.1467-9760.2009.00342.x

Benhabib, S. (1996). Toward a deliberative model of democratic legitimacy. In Democracy and difference: Contesting the boundaries of the political, ed. S. Benhabib. Princeton, NJ: University of Princeton Press.

Dewey, J. (1916). Democracy and education. New York: MacMillan.

Elster, J. (1998). Deliberative democracy. Cambridge: The University of Cambridge. https://doi.org/10.1017/CBO9781139175005

Gerard, S. M. (2003). Who are the actors in the governance of French universities? The paradoxal victory of deliberative leadership. Higher Education, 45, 71-89. https://doi.org/10.1023/A:1021297532346

Glickman, C. D. (1998). Revolutionizing American's Schools. San Francisco: Jossey-Bass.

Gorsuch, R. L. (1983). Factor analysis (2nd ed.). Hillsdale, NJ: Lawrence Erlbaum.

Gutman (1987). Democratic Education. Princeton, NJ: Princeton University Press. https://doi.org/10.1515/9781400826339

Gutmann, A., \& Thompson, D. (2004). Why deliberative democracy? . Princeton: Princeton University Press.

Habermas, J. (1996). Between facts and norms: Contributions to a discourse theory of law and democracy. Cambridge, MA: MIT Press.

Kaiser, H. F. (1974). An index of factorial simplicity. Psychometrika, 39, 31-36. https://doi.org/10.1007/BF02291575

Leech, N. L., Barrett, K. C., \& Morgan, G. A. (2005). SPSS for intermediate statistics; use and interpretation (2nd Ed.). Mahwah, NJ: Lawrence Erlbaum.

Roth, K. (2004). Deliberative Pedagogy and Deliberative Communication as an Evaluative Procedure. In R. Premfors, \& K. Roth (Eds.) Deliberativ demokrati (Deliberative Democracy) (pp. 77-114). Lund: Studentlitteratur.

Samuelsson, M. (2016). Education for deliberative democracy: A typology of classroom discussions. Democracy \& Education, 24(1), Article 5. Retrieved from http://democracyeducationjournal.org/home/vol24/iss1/5

Shechyman, Z. (2002). Validation of the democratic teacher belief scale. Assessment in Education, 9(3), 363-378. https://doi.org/10.1080/0969594022000027672

Simonton, K. D. (1986). Presidential personality: Biographical use of the Gough adjective check list. Journal of Pesonality and Socail Psychology, 51, 149-283. https://doi.org/10.1037/0022-3514.55.6.928

Simonton, K. D. (1987). Why Presidents Succeed:A political psychology of leadership. New Haven, CT: Yale University Press. https://doi.org/10.2307/j.ctt1xp3nh2

Simonton, K. D. (1988). Presidential style: Personality, biography, and performance. Journal of Personality and Social Psychology, 55, 928-936. https://doi.org/10.1037/0022-3514.55.6.928

Simonton, K. D. (2006). Presidential IQ, openness, intellectual brilliance, and leadership: Estimates and correlations for 42 U.S. Chief Executives. Political Psychology, 27(4), 38. https://doi.org/10.1111/j.1467-9221.2006.00524.x

Spillane, J. P. (2006 ). Distributed leadership. San Francisco: Jossey-Bass.

Spillane, J. P., Camburn, E., \& Pareja, A. (2007). Taking a distributed perspective to the school principal's workday. Leadership and Policy in Schools, 6, 103-125. https://doi.org/10.1080/15700760601091200

Stokes, C. (2002). 'Democracy and citizenship' in A. Carter and G. Stokes (eds), Democratic Theory Today. Cambridge: 
Polity Press.

Tabachnick, B. G., \& Fidell, L. S. (2001). Using multivariate statistics (4th ed.). New York: Harper \& Row.

Wegerif, R. (2005). Reason and creativity in classroom dialogues. Language and Education, 19(3), $223-237$. https://doi.org/10.1080/09500780508668676

Woods, P. A. (2004). Democratic leadership: Drawing distinctions with distributed leadership. International Journal of Leadership in Education: Theory and Practice, 7(1), 3-26. https://doi.org/10.1080/1360312032000154522

Woods, P. A. (2005). Democratic leadership in education London: Sage Publications.

Woods, P. A., \& Gronn, P. (2009). Nurturing Democracy. Educational Management Administration \& Leadership, 37(4), 430-451. https://doi.org/10.1177/1741143209334597

Young, I. M. (1996). Communication and the other: Beyond deliberative democracy. In S. Benhabib (Ed.) Democracy and difference: Contesting the boundaries of the political (pp. 120-135). Princeton, NJ: Princeton Univ. Press.

\section{Copyrights}

Copyright for this article is retained by the author(s), with first publication rights granted to the journal.

This is an open-access article distributed under the terms and conditions of the Creative Commons Attribution license which permits unrestricted use, distribution, and reproduction in any medium, provided the original work is properly cited. 